\title{
Emin is Screaming: Empathy as Affirmative Engagement in Tracey Emin's Homage to Edvard Munch and All My Dead Children (1998)
}

\section{Clare Johnson}

In 2008 Tracey Emin's short film Homage to Edvard Munch and All My Dead Children (1998) was exhibited at the Scottish Gallery of Modern Art in Edinburgh. Positioned as the penultimate exhibit in Emin's first retrospective the film was preceded by an emotive repertoire of personal narratives pivoting around Emin's dual identity as successful artist and sexual woman, her creativity born out of the pleasures, pains, disappointments and sadnesses of her procreative self. The location of the film within the exhibition is important not only because the viewer arrives at the work with heightened consciousness of the emotional intensity of Emin's experiences, but because the looped film does not wait patiently for the viewer's arrival, instead calling to the unsuspecting gallery visitor with an almighty scream that punctures the relative calm of the preceding two rooms; the contemplative atmosphere ruptured by the sound of one woman's anguish. The notion of spectatorship is inadequate for this experience as we are thrown into the midst of Emin's despair via sound rather than image. Through my encounter with the sound-image combination of Emin's film I call into question the concept of spectatorship, which, as Michel Chion has argued continues to dominate film studies despite the inextricable link between sound and image in both mainstream and avant-garde cinema ${ }^{\text {i }}$ Emin's scream is guttural and disconsolate. In the Edinburgh show it could be heard before and beyond the imagery. There was a collision of tenses as the irruption of the scream in the present tense of my viewing the artworks in the preceding room crashed into the anticipation of what I was about to find in the next room.

Homage to Edvard Munch starts with the naked Emin curled up in a foetal position, isolated on a wooden jetty at the edge of the Oslo Fjord, which is the location used in Munch's 1893 painting The Scream. The camera pans around the water, which glistens in the sunlight. We then hear Emin scream for what feels like an eternity, but is in fact less than a minute. On my viewing this induced a momentary panic and an exchange of concerned glances amongst strangers in the gallery, an imagined community that temporarily shared a feeling of fear that this sound may not have emanated from an artwork and may not, therefore, be cloaked in art historical reference. Barely resisting the temptation to run to the room in which Homage to Edvard Munch was exhibited, I was relieved to discover the sign value of the scream, its existence as a textual component of the two minute 10 second Super 8 film. The scream endured for longer than it took me to find its source; the imperative to be heard not satisfied by the viewer's presence as the film continues to play on a loop. I watched the film several times over, but never lost the feeling of anxiety in the pit of my stomach induced by that initial gut-wrenching scream.

In this article I want to argue that the affective resonance of Emin's film is not solely at the level of what is represented (it is not simply a representation of traumatic events, although this is also the case), but rather is the occasion for an empathic encounter between artist-as-artwork and viewer-collaborator, which is necessarily affirmative in its co-emergence of the 'work' of art. I ask what an affirmative 
encounter with this particular artwork enables us to do. Empathy requires the listener to say yes to the one who speaks, to allow space for his or her story and remain open to this testimony. It is to say yes to the experience of another rather than treat it with suspicion, thus refusing critical models that centre on the veracity of Emin's work (did the event she speaks of really happen, is her art autobiographically accurate?). Such models aim to distinguish between story and truth as if unmediated experiences were possible in art. Empathy, on the other hand, involves a willingness to affirm the story of another and is, therefore, an alternative to the tendency to deconstruct experiences as they are figured in texts. An empathic encounter with art does not treat the work as a representation of prior experience or something that already exists in the world. In remaining open to the testimony of another the audio-viewer is transformed into a co-producer of the work, their experiences meeting those of the artist. Thus an affirmative engagement with art has a different temporality to representation; as something dependent on the one who listens the 'work' is emergent, unfinished and future-oriented.

An empathic encounter asks not only what the artwork means, but how it feels as a shared responsibility between these two actors. As a researcher, rather than visitor to an exhibition, I am interested to explore what it means to empathise with an artwork, why this particular film elicits this reaction in me and how this might contribute to an affirmative politics of art. Methodologically, I address these questions by putting into dialogue my experience of Emin's film, writing on empathy as this relates to art, and theories that engage with the relation between textuality and the 'real' in screen-based media forms. My intention is to move towards a working definition of empathy that takes its cues from the affective pull of Emin's film. As a key component of this development I argue for the 'inhabitation of difference' as a necessary condition for an empathic encounter with art.

Empathy research has largely been the domain of counseling, psychotherapy, and social and developmental psychology. Much of the existing literature on empathy is based on the counselor/client relationship. Various definitions follow including 'vicarious introspection, , , temporarily living in the client's world ${ }^{\mathrm{iii}}$ and 'transposing oneself into the thinking, feeling and acting of another'. ${ }^{\text {iv }}$ With the exception of Jill Bennett's important work on empathic vision there is little written about empathy in relation to contemporary art. ${ }^{\mathrm{V}}$ The relationship between art and empathy does, however, emerge within writing on affect, memory and trauma, and this provides a conceptual framework that differs from approaches rooted in psychology.

Nevertheless, there is room for greater consideration of empathy as part of the work that art does when approached through affirmation. This article aims to contribute to the development of this field.

\section{Inhabiting difference}

In his recent work on empathy and the position of the witness in screen-based media forms John Ellis notes that empathy depends on 'the attribution of personhood to the other in order to be able to feel from their position'. vi In my reaction to Emin's scream I realize that it is not simply a question of how the sound of her pain makes me feel as an individual respondent, or a transposition of my feelings on to the work, but a sense that I identify with her distress despite not having experienced the trauma of lost 
children to which the work refers. I know I cannot feel what she feels, but despite the gap in experience (maternal, cultural and sexual) I empathise with her scream and the personal story that I have come to know of her life through artworks, television appearances, interviews, her feature length film (Top Spot, 2004) and book (Strangeland, 2005). I agree with Ellis when he claims that 'witnesses have to recognize the other as being like themselves if they are to experience empathic emotions', but argue that there is a difference between similarity and sameness. ${ }^{\text {vii }}$ To be like something is not to be it and recognition of this difference is necessary for an empathic encounter. The separation between subject and object that exists in the encounter with art (albeit sometimes partial or contested) does not fully account for the distance that enables my empathic response to Homage to Edvard Munch. After all, not all artworks inspire this reaction. There is something specific within the narrative of the film that engages my own memories of adolescence and it is in my failed desire to bridge the gap between subject and object - to fully identify with the artwork - that I acknowledge Emin's life-force as other to mine.

As I examine why I think I can feel from Emin's position I begin to question my own desire for an empathic relation with the work. I am conscious of the potential for class tourism via the spectacle of despair. Emin's working-class upbringing in Margate is not reflected in my own adolescence, which was spent near (but not in) Bournemouth, another seaside town on the English south coast. Perhaps my desire to empathise with her story of traumatic sexual realisation is a desire for the working-class femininity denied in my own adolescence, both geographically and culturally, by growing up in the middle-class outskirts of Bournemouth. In a reversal of Beverley Skeggs' argument about the aspiration to middle-class respectable femininity, I now understand my teenage frustration at the safe distance separating me from the bright lights (most often triggered by inadequate bus timetables) as an acute desire to lose middle-class respectability. ${ }^{\text {viii }}$ What Emin narrates as the habitual struggles of her adolescence from within a seaside town were experienced from outside as a fantasy of adventure. The gap that prevents me from claiming Emin's experience as my own is a function of differences in class and geography. This gap amplifies the distance that already exists between subject and object, audio-viewer and artwork. Where Emin repeatedly narrates her desire to escape the working-class realities of a rundown seaside town I have never lost the desire to get in.

The similarity of experience upon which these differences become personally meaningful concerns the gendering of memory. The artworks contained within the Edinburgh exhibition were about the (re)construction of memories, for example of maternal loss, adolescent experience and sexual exploitation. The form of the retrospective exaggerates and extends this sense of memory to locate Emin within an institutional and art historical framework. The retrospective is an active remembering, which simultaneously produces and celebrates an artist's legacy. However, the tradition of the retrospective and the memory-work of Emin's oeuvre are differently gendered. Whereas the retrospective is an art historical trope used to secure the dominance of patrilineal control and influence emanating from a celebrated individual, the memory-work of Emin's practice constructs a sense of fragility that beckons the experiences of the women who are drawn to the work. It is as though Emin relishes the opportunity to have the legitimation of a retrospective bestowed upon her so that she can play with the narration of gendered memory (sexual and 
artistic) that her work has always focused on. Thus, I empathise with the artwork as 'event', not the artwork as a discrete object. The curatorial decision to position Homage to Edvard Munch as the penultimate exhibit in the Edinburgh retrospective, such that its sonic properties spill out into the sound-image space of other works, is indistinguishable from the gendered pleasure of this particular encounter.

In trying to understand why Emin's work matters to me I realize that the affirmative engagement I hold dear is not only with Emin's experience, but with my own. My reasons for escaping the English south coast are different to Emin's - where her escape was fuelled by humiliation and despair (encapsulated in her scream) mine was driven by the desire for other-worldliness. Where she has held on to her childhood experiences as a source for her art, my encounter with Emin's work affirms personal regret that I let mine go. They are not alive for me in the way that Emin's life story is for her. I have allowed my memories of this time to fade in an attempt to create my life anew. Thus affirmation of Emin's life-as-work enables a (sometimes painful) dialogue between my current and former selves.

The gap between Emin's experience and my own produces empathy - a realisation of the different affects involved (my disappointment, Emin's pain) - without reducing the artist's experience to my own. In the context of art theory, Jill Bennett draws on Gayatri Spivak's notion of encounter to argue that in giving testimony 'the difference between the one who testifies and the listener is not necessarily eradicated, although it may be reduced; it is, more precisely, inhabited ${ }^{\text {, ix }}$ It is by inhabiting the difference in experience that an ethics of listening can take place in which the subjectivity of the other is affirmed rather than appropriated or subsumed into the experience of the self. I am aware of the unbridgeable gap between Emin's despair and my anxiety; the strength of her feeling seems unreachable. Thus, empathy can be understood as a near-identification with the feelings of another, but this nearness contains within it a distance because to be near something is to be not quite there.

In my reaction to Emin's film a model of empathy starts to develop which diverts from the counselor/client relationship that informs psychological models of empathy research. In these approaches the encounter is assumed to be face-to-face and the counselor's empathy is understood as something that will help the client. However, in empathising with something on screen the potential for reciprocity is lost because, although readings of artworks are at their most powerful when the artwork is treated as a fellow subject, my encounter with Homage to Edvard Munch is not subject-tosubject in the sense of a real time counselor-client relationship. Here we are dealing with a different temporality in which the attempt to feel from the position of the other has been transposed into the durational movement of the gallery visitor and mediated by the expectations, histories and conventions of the artworld. Part of my frustration is the knowledge that my empathy will not help Emin. As Ellis argues the mobility of vision that characterizes film and television enables us to feel, but comes at the expense of being unable to intervene. ${ }^{\mathrm{x}}$ I can witness but I cannot act, thus I cannot stop the scream or do anything to take away the pain that causes it. Where the possibility of action is removed this seems only to increase my level of identification with the affective force of the film, if not the specific affect experienced by Emin. The possibility of changing the circumstances or mood of another turns out not to be a 
prerequisite for empathy. In short, we need a way to theorise empathy outside of the potential for impact.

\section{Temporal complexity}

The dominance of formal and semiotic modes of analysis in $20^{\text {th }}$ century European and North American art history has foreclosed other approaches to understanding the ontological status of art. We are used to asking what and how art means, but less inclined to ask how art makes us feel or what art does. The orthodoxy of sign value saturates visual practice to the extent that it is difficult to think about art outside of textuality and visual language or without this being the default position against which others are measured. This perceptual framework situates the artwork as a representation to be understood, decoded, challenged and mined for social meaning, whilst assuming an absence of the referent. It is deconstructive rather than affirmative. This has diverted attention away from a series of other ideas including art as process, art as matter and materiality, art as affective encounter and art as empathic relation. These ideas provoke forms of temporality that are durational and performative; for example, the notion that art brings into being that which it pictures suggests a futurity, which differs from the anteriority of representation, its existence as a substitute for something else that is already there ${ }^{\mathrm{xi}}$ The language of textuality is inadequate in this instance because it cannot grasp the timbre of Emin's film. Rather than only existing as a code to be interpreted Homage to Edvard Munch generates an atmosphere to be felt, a palpable sense of loss which is affirmed through my empathy. Thus, although useful for the politically important task of deciphering social meaning, the temporality inscribed within the logic of representation cannot speak to the urgency of Emin's film, the affective power of which has an equally important political resonance if feelings are not to be relegated to the too-often feminised category of non-academic discourse.

So what if the gap between signifier and referent collapses such that the absence that figures representation is rendered temporarily obsolete. What if rather than standing in for something else, a prior reality, art is the real. On my viewing the scream in Emin's film temporarily exceeded representation, thrusting me out of what I know into the uncertainty of the as-yet-unknown. For a second the scream punctured both the signification of the film (it was the referent) and the institutionalized framing of the gallery system. Sound is, however, also representational (the scream functions as a signifier), but in the slippage of time between hearing and seeing the 'event' of Emin's film a fantasy of transcendence was possible in which the scream could be imagined as autonomous and present to itself. ${ }^{\text {xii }}$

In one sense it is akin to the punctum, yet whereas Roland Barthes described this as '[an] element which rises from the scene, shoots out of it like an arrow' the scream in Homage to Edvard Munch feels separated from the imagery both in the temporality of its positioning within the retrospective and in the relation of sound to image within the film itself. ${ }^{\text {xiii }}$ We see Emin's body and we hear the scream, but do not see Emin screaming. Nevertheless, despite the disembodied nature of this scream I feel sure that the sound is hers (that she owns it). Neither does the scream emanate as if from a 
position off-screen; it is clearly a crucial component of the film and is in no way incidental to the imagery. This sonic ambiguity is an example of what Chion calls the acousmetre, a sound that is neither wholly inside nor outside the image. ${ }^{\text {xiv }}$ The scream simultaneously belongs to Emin and exceeds the specificity of her situation, which makes it easier for the audio-viewer to identify with an abstracted manifestation of anguish. A series of temporal dislocations are apparent between sound and image within the film and within the event of my encounter. This slippage sets in motion the possibility of an empathic response as I try to grasp the feeling of another only to be reminded of the gap between the one who testifies and the one who listens. The representational play reminds me of my position as not-Emin (her experience is pictured before me) only for the intensity of her scream to plunge me back into the fantasy of nearness. Indeed, this lack of instrumentality in Emin's practice, often misread as lack of control, is precisely why it is so appealing for anyone wishing not to master but to immerse her/himself in Emin's world.

\section{Empathy and reproduced image/sound}

The scream operates as a catalyst for empathy (who would not at least try to imagine why it has come to this), but is never completely recouped into visual language despite the many ways in which the film reminds the viewer of its sign function. The imagery is seductive, emphasizing the surfaceness of the water until it fills the screen as pattern overlaid with the sound of lapping waves. The sea, however, is only visually recognizable as the light dances across it - it is surface rather than substance - and no attempt has been made to hide the refraction of light through the camera lens: it is filmed sea. There are also aesthetic references. Emin's pose is reminiscent of Edward Weston's photographs of Tina Modotti and the location of Munch's Expressionist painting is rendered cinematic in its appeal to what might be lost at sea. The call to particular photographic, painterly and filmic tropes, practices and techniques heightens the mediated aspect of the film as if this ought to remind us of its signifying function, its reference to something outside of itself, and thus act as a defense against the affective power of the scream. However, as I continue to try to feel from Emin's position I realize that this recuperation is incomplete. I cannot confine the film to its sign value and the textuality of the work only partially protects me from the irruption of the scream.

The propensity of screen media to be experienced as both intensely felt and textual sign is explored by Ellis who notes the 'thereness' of recorded sound and image, its felt effect, despite our knowledge of its textuality. ${ }^{\mathrm{xv}}$ Far from disenfranchising affect textuality can render it more real, increasing its thereness, because in re-presenting an affect via film it is affirmed in the here and now of our viewing and hearing. In this sense Emin's scream is multi-directional in its temporality referring simultaneously to events remembered from the past, the artist's enduring experience of anguish and the present tense of our encounter with the film. For me this encounter is marked by my desire for proximity to the real, a yearning to bring things closer both visually and affectively. In his work on liveness and mediatization Philip Auslander has argued that the increased level of intimacy offered by screen-based media forms is now so inculcated in everyday expectations of what constitutes the real that it is habitually included in live performances. ${ }^{\text {xi }}$ Close-ups on large screens at football matches, for 
example, picture what the naked eye cannot see thus compensating for the disappointment of the real. There is, following Auslander, a complex relationship between representation and intimacy in which the absence of the referent becomes a mechanism by which affective power is increased rather than diminished. Auslander shows us that screen-based representations are not necessarily counter-affectual and can often be closer to what we experience as the real. My enduring preference for Emin's films over her drawings or monoprints, which have been problematically understood as a more direct form of expression, attests to Auslander's argument. ${ }^{\text {xvii }}$ Furthermore, my preference for the sound of Emin's recorded voice over the experience of hearing her speak live, fascinating though this is, speaks to the same point. My sense of empathy with Emin's affective repertoire is heightened when experienced through reproduced image or sound. It is not dependent on a real-time encounter.

Some recent literature within what we might call the affective turn has tended to celebrate affects' capacity to move beyond representation, but I wish to distinguish between this claim and the argument proposed here in which the film moves in and out of different temporal registers. Simon O'Sullivan, for example, reads affect as a welcome departure from the orthodoxy of semiotic, interpretive and deconstructivist approaches to art. ${ }^{\text {xviii }}$ Drawing on Deleuze and Guattari, O'Sullivan argues for an understanding of art as affirmative practice. This is an exciting prospect. However, the temporality of the model proposed in which affect is understood as the answer to the inability of social determinism to deal with the unpredictable, the unexpected or the 'texture' of social experience is itself problematic when read through the dynamic of Emin's practice. The idea of art beyond representation suggests a displacement activity and leads to the countering of affect celebration with affect repulsion; for example, a fear amongst some feminist scholars that affect celebration corresponds to a waning of interest in feminist critical methodologies, in particular those informed by notions of ideology and textuality. ${ }^{\text {xix }}$ However, the paradox of the work of art that moves between the anteriority of representation and the present tense of empathy belies a clear distinction between affect and textuality.

\section{The work of affirmation}

By engaging with Emin's film as an affirmative encounter the beginnings of a new conceptual vocabulary for studying empathic relations with art comes into view. This includes the inhabiting of difference, the incomplete recuperation of affect into the logic of representation, the production of intimacy via the rhetoric of the screen, and the productive complexity of tenses.

If empathy is a partially failed attempt to feel from the position of the other it suggests a belief in the possibility of change, an affirmative encounter made possible by the movement between what-is and what is set before me as a picture, real-time affect and textuality. The film metaphorically enacts a changing of perspective, zooming out such that it is objectified as a representation, then zooming in so close that I am implicated in the work through my necessarily failed attempt to live, albeit temporarily, in Emin's world. 
The labour involved in creating the conditions for empathy, whether fulfilled or not, calls to mind Barbara Bolt's important observation that 'The 'work' that art does, is categorically not the object - painting, sculpture, drawing, print and so on - that we have come to call an artwork' ${ }^{x}$ Homage to Edvard Munch is a powerful film, but this power does not derive from its status as an artwork in the sense of an object or entity amenable to categorisation. The work involved in affirming Emin's experience is carried out both by the artist and audio-viewer in a form of co-creativity. It is not straightforward or effortless. On the contrary the weight of no-saying that surrounds art criticism, derived from Marxist methodologies that focus on ideological motives and structural conditions, makes yes-saying a difficult task. It is to work against the tide of rhetoric about progress and intellectual rigour in art and analysis. In addition, the discursive construction of Emin in particular as self-obsessed, lacking control or self restraint (creatively and sexually), as a bad artist or not even an artist at all makes this a peculiarly challenging prospect. There are constant reminders of why we should say no to Emin. However, the reluctance to say yes to Emin's work and experience, for fear of appearing celebratory and uncritical, severely limits our encounter with her art. This only makes affirmation as a form of critical engagement more imperative.

To say yes in the way I have proposed requires a temporary aligning of self to other, a partial loss of distance more commonly associated with complicity than critique. It is an additive process, not a deconstructive project. To affirm someone else's experience risks the loss of critical distance, but it is a risk worth taking in the interests of conceptualising other ways of understanding our encounter with art. An empathic relation opens up new questions such as who occupies which position. The roles of critic, artist, audio-viewer and witness shift within the dialogue between my experience and Emin's such that there is no privileged position from which the art event emerges and no sovereign voice of the critic. It is a performative process that cannot be reduced to a single authored text.

The empathy that draws me close to the film, whilst simultaneously emphasizing the distance between my experience and Emin's, is gendered at both a literal and methodological level. It is not surprising that maternal loss elicits a gendered empathic response. However, the fear of the referent - the idea that Emin's scream does not represent something else but is the real - discloses the masculinist anxiety of visual culture studies in which proximity negates mastery and female sexuality cannot be held safely at a distance. Despite the ubiquity of representationalist thinking Emin is screaming.

\section{Notes}

I would like to thank Dr Julia Moszkowicz for her helpful comments on this article.

\footnotetext{
${ }^{\mathrm{i}}$ Michel Chion, Audio-Vision: Sound on Screen [1990], trans. Claudia Gorbman (New York: Columbia University Press, 1994), p.xxv.

ii Heinz Kohut, The Analysis of the Self (New York: International Universities Press, 1971), p.1-37.
} 
iii Carl Rogers, 'The Necessary and Sufficient Conditions of Therapeutic Personality Change' Journal of Counseling Psychology, 21 (1957), pp.95-103.

${ }^{\text {iv }}$ Rosalind F. Dymond, 'Personality and Empathy', Journal of Consulting and Clinical Psychology, 14 (1950), pp.343-350. For an overview of the literature on empathy see Changming Duan and Clara E. Hill, 'The Current State of Empathy Research', Journal of Counseling Psychology, 43:3 (1996), pp.261-274.

' Jill Bennett, Empathic Vision: Affect, Trauma and Contemporary Art (Stanford, California: Stanford University Press, 2005).

vi John Ellis, 'What Are We Expected to Feel? Witness, Textuality and the AudioVisual', Screen, 50:1 (2009), p.73.

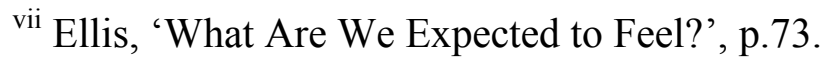

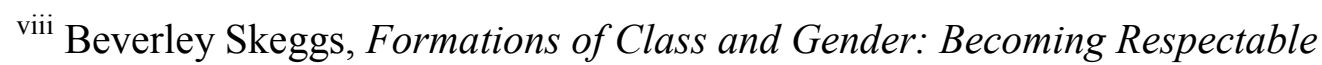
(London: Sage, 1997), pp.17-41.

ix Jill Bennett, Empathic Vision, p.105, my emphasis.

${ }^{x}$ John Ellis, 'What Are We Expected to Feel?', p.71.

${ }^{x i}$ Here I am employing Judith Butler's concept of the performative speech act that brings into being that which it names. See Judith Butler, 'Performative Acts and Gender Constitution: An Essay in Phenomenology and Feminist Theory', Theatre Journal, 40:4 (1988), pp.519-531.

${ }^{x i i}$ Brian Massumi has argued that the importance of affect lies in its automony, its existence outside social signifying structures. Massumi highlights the movement and vitality that is missed by an interpretive critical framework that focuses on the already-known. See Brian Massumi, Parables for the Virtual: Movement, Affect, Sensation (Durham \& London: Duke University Press, 2002), pp.23-45.

xiii Roland Barthes, Camera Lucida [1980], trans. Richard Howard (London: Fontana, 1990), p.26.

xiv Michel Chion, Audio-Vision: Sound on Screen, pp.129-131.

${ }^{\mathrm{xv}}$ John Ellis, What Are We Expected to Feel?', p.68.

${ }^{x v i}$ Philip Auslander, Liveness: Performance in a Mediatized Culture (London \& New York: Routledge, 1999), p.35.

xvii Chris Townsend has argued that Emin's monoprints are read as a raw and unmediated form of expression, in particular her use of lettering including mis-spelt words, despite the careful consideration required to construct each monoprint, which involves writing backwards quickly, before the ink dries. See Chris Townsend, 'Heart of Glass: Reflection, Reprise and Riposte in Self-Representation', in The Art of Tracey Emin, ed. Mandy Merck \& Chris Townsend (London: Thames \& Hudson, 2002), pp.79-101. 
xviii Simon O'Sullivan, Art Encounters Deleuze and Guattari: Thought Beyond Representation (Basingstoke: Palgrave Macmillan, 2006), pp.9-38.

${ }^{\text {xix }}$ See, for example, Imogen Tyler, 'Methodological Fatigue and the Politics of the Affective Turn', Feminist Media Studies, 8:1 (2008), pp.85-90.

xx Barbara Bolt, Art Beyond Representation: the Performative Power of the Image (London \& New York: I.B. Tauris, 2004), p.88.

\section{$\underline{\text { Biographical note }}$}

Clare Johnson is a Senior Lecturer in Visual Culture in the Faculty of Creative Arts, University of the West of England. Her research interests include femininity, feminist art practice and visual culture. Her forthcoming article 'Preposterous Histories: maternal desire, loss and control in Carolee Schneemann's Interior Scroll (1975) and Tracey Emin's I've Got It All (2000)' will be published in Feminist Media Studies, $10: 3(2010)$.

Dr Clare Johnson

School of Creative Arts

University of the West of England

Bower Ashton Campus

Kennel Lodge Road

Bristol

BS3 2JT

Tel: +44 (0)1173284716

Clare.Johnson@uwe.ac.uk 